\title{
Glial Cell Line-Derived Neurotrophic Factor and Chronic Electrical Stimulation Prevent VIII Cranial Nerve Degeneration Following Denervation
}

\author{
SHO KANZAKI, ${ }^{1,2}$ TIMO STÖVER ${ }^{3}$ KOHEI KAWAMOTO, ${ }^{1,4}$ DIANE M. PRIESKORN,${ }^{1}$ \\ RICHARD A. ALTSCHULER, ${ }^{1}$ JOSEF M. MILLER, ${ }^{1,5}$ AND YEHOASH RAPHAEL ${ }^{1 *}$ \\ ${ }^{1}$ Kresge Hearing Research Institute, University of Michigan, Ann Arbor, Michigan 48109-0648 \\ ${ }^{2}$ Department of Otolaryngology, Keio University, Shinjuku, Tokyo 160-0016, Japan \\ ${ }^{3}$ ENT Clinic of the Medizinischen Hochschule Hannover, 30625 Hannover, Germany \\ ${ }^{4}$ Department of Otolaryngology, Kansai Medical University, Moriguchi, Osaka 570-8506, Japan \\ ${ }^{5}$ Department of Otolaryngology, Karolinska Institute, Stockholm, S 17176 Sweden
}

\begin{abstract}
As with other cranial nerves and many CNS neurons, primary auditory neurons degenerate as a consequence of loss of input from their target cells, the inner hair cells (IHCs). Electrical stimulation (ES) of spiral ganglion cells (SGCs) has been shown to enhance their survival. Glial cell line-derived neurotrophic factor (GDNF) has also been shown to increase survival of SGCs following IHC loss. In this study, the combined effects of the GDNF transgene delivered by adenoviral vectors (Ad-GDNF) and ES were tested on SGCs after first eliminating the IHCs. Animal groups received Ad-GDNF or ES or both. Ad-GDNF was inoculated into the cochlea of guinea pigs after deafening, to overexpress human GDNF. ES-treated animals were implanted with a cochlear implant electrode and chronically stimulated. A third group of animals received both Ad-GDNF and ES (GDNF/ES). Electrically evoked auditory brainstem responses were recorded from ES-treated animals at the start and end of the stimulation period. Animals were sacrificed 43 days after deafening and their ears prepared for evaluation of IHC survival and SGC counts. Treated ears exhibited significantly greater SGC survival than nontreated ears. The GDNF/ES combination provided significantly better preservation of SGC density than either treatment alone. Insofar as ES parameters were optimized for maximal protection (saturated effect), the further augmentation of the protection by GDNF suggests that the mechanisms of GDNF- and ES-mediated SGC protection are, at least in part, independent. We suggest that GDNF/ES combined treatment in cochlear implant recipients will improve auditory perception. These findings may have implications for the prevention and treatment of other neurodegenerative processes. J. Comp. Neurol. 454:350-360, $2002 . \quad \odot 2002$ Wiley-Liss, Inc.
\end{abstract}

Indexing terms: gene transfer; growth factors; spiral ganglion; cochlea; guinea pig; cochlear implant

\begin{abstract}
Cranial nerve degeneration secondary to denervation is a common finding in the nervous system (Springer and Kitzman, 1998). Cochlear inner hair cells (IHCs) normally provide excitatory activation of the auditory nerve, the VIII cranial nerve. Following the loss of IHCs from trauma or degenerative disease, auditory neurons degenerate (Otte et al., 1978; Webster and Webster, 1981; Shepherd et al., 1983; Sutton, 1983; Jyung et al., 1989; Leake et al., 1991; Nadol and Hsu, 1991). Absence of both excitatory activity and chemical survival factors has been implicated in the loss of auditory neurons (Bohne and Harding, 1993) following deafness. Reintroducing excitation
\end{abstract}

Grant sponsor: National Institute of Health-National Institute on Deafness and Other Communication Disorders; Grant number: DC00078; Grant number: DC03820; Grant number: DC05188; Grant sponsor: Royal National Institute for the Deaf (RNID); Grant sponsor: Ruth and Lynn Townsend Professorship.

*Correspondence to: Yehoash Raphael, Kresge Hearing Research Institute, MSRB 3, Room 9303, 1150 W. Medical Center Dr., Ann Arbor, MI 48109-0648. E-mail: yoash@umich.edu

Received 29 October 2001; Revised 13 June 2002; Accepted 6 September 2002.

DOI $10.1002 /$ cne. 10480

Published online the week of October 28, 2002 in Wiley InterScience (www.interscience.wiley.com). 
to the auditory nerve following IHC loss using chronic cochlear electrical stimulation (ES) has been shown to greatly reduce the deafness-related loss of spiral ganglion cells (SGCs) (Lousteau, 1987; Hartshorn et al., 1991; Leake et al., 1991; Miller et al., 1997; Mitchell et al., 1997), although there have also been reports that ES is not always protective (Shepherd et al., 1994; Araki et al., 1998; Li et al., 1999). The mechanism through which ES enhances SGC survival is not completely understood. In vitro studies on explanted SGC neurons have shown a depolarization-induced enhancement of SGC survival that is mediated by L-type voltage gated $\mathrm{Ca}^{2+}$ channels (Hegarty et al., 1997). It has recently been shown in vivo that blocking L-type voltage-gated $\mathrm{Ca}^{2+}$ channels eliminates the protective effective of ES (Miller, 2001), supporting this mechanism for chronic ES-induced survival of SGC following deafness. These observations indicate that ES may enhance cell survival by maintaining intracellular $\mathrm{Ca}^{2+}$ levels within a physiological range.

Chronic perilymphatic infusion of chemical survival factors has also been shown to reduce SGC loss following loss of IHC. Effective survival factors include neurotrophins (Ernfors et al., 1996; Staecker et al., 1996; Miller et al., 1997), GM1 ganglioside (Walsh and Webster, 1994), and the neurotrophic factor glial cell line-derived neurotrophic factor (GDNF; Ylikoski et al., 1998). Introduction of GDNF by adenoviral vector has also been shown to enhance SGC survival following deafness (Yagi et al., 2001).

It is not known whether the pathways by which the different survival factors, including ES, achieve enhanced SGC survival are independent or overlapping. A combination of the neurotrophins brain-derived neurotrophic factor (BDNF) and neurotrophin 3 (NT3) was shown to have additive survival effects in vitro (Mou et al., 1997, 1998); however, an in vivo study demonstrated that a "cocktail" of chemical survival factors was no more effective than when they were applied singly (Miller et al., 1997). In the present in vivo study, we examined the effects of the combined application of a chemical survival factor and ES compared with the effects of a single protective factor (ES or chemical survival factor). GDNF was used as the chemical survival factor and was applied via an adenoviral vector.

GDNF, a member of a relatively new family of trophic factors related to the transforming growth factor- $\beta$ superfamily, was initially isolated and cloned as a factor produced by B49 rat glial cells with pronounced trophic effects on cultured fetal rat midbrain dopamine neurons (Lin et al., 1993, 1994). GDNF is synthesized by many cell types throughout the body and affects the development and survival of a diverse set of neuronal and nonneuronal cells (Henderson et al., 1994; Trupp et al., 1995; Moore et al., 1996; Pichel et al., 1996; Sanchez et al., 1996; BujBello et al., 1997).

In the normal mammalian inner ear, GDNF mRNA is expressed in developing outer hair cells (OHCs) and IHCs as well as in mature IHCs (Ylikoski et al., 1998). The GDNF receptor GFR $\alpha 1$ (formerly GDNFR $\alpha$ ) is expressed in SGCs (Ylikoski et al., 1998; Stöver et al., 2000, 2001). GDNF has been shown to be up-regulated after trauma to the inner ear (Nam et al., 2000) and to enhance SGC survival after IHC loss (Miller et al., 1997; Yagi et al., 2001). The protective effects of GDNF on SGCs are mediated by binding and activation of the two GDNF receptors. Once activated, GDNF is thought to promote cell survival through intracel- lular signaling via the cAMP responsive element-binding (CREB) and phosphatidylinositol 3-kinase (PI3K) pathways (Xing et al., 1998; Feng et al., 1999; Hayashi et al., 2000). However, the exact signaling cascade is not completely clear at present.

There are several ways to introduce therapeutic molecules such as growth factors into the inner ear. One approach is to inoculate the protein itself. The main disadvantages of this approach are degradation by proteases, requiring continuous administration, and potential immune response against the protein. Gene transfer is an alternative, in which the specific gene is incorporated into cells, leading to the synthesis of the required protein (Barkats et al., 1998). This is especially attractive when the necessary protein is a secreted and diffusible molecule, as is the case with growth factors; it is particularly appropriate in organs such as the eye or the inner ear, where the gene product can be secreted directly into the fluid bathing the target cells.

Delivery of GDNF by an adenovirus vector has been tested for several neurological applications. For instance, administration of Ad-GDNF into the vitreous body of rat eyes enhanced survival of axotomized retinal ganglion cells (Schmeer et al., 2002). In another study, Ad-GDNF was injected into muscle tissue of amyotrophic lateral sclerosis model mice. Survival of motor neurons in treated muscles was significantly increased compared with controls (Manabe et al., 2002).

The cochlea possesses several advantages as a target organ for gene transfer. Although it is encased in the temporal bone, inoculation with vectors is technically feasible. The otic capsule isolates the inner ear fluids and tissues and reduces the spread of viral particles and secreted protein to adjacent tissues. The endolymphatic duct and the cochlear aqueduct, which connect the cochlea to other areas, have a very limited flow. The cochlear fluids allow diffusible particles, such as viruses or proteins, to disperse rapidly throughout the cochlea and facilitate their ready access to the SGCs. Adenovirus vectors have been used for gene transfer into several organs, including the inner ear, where the most efficiently transduced cells are the mesothelial cells lining the perilymphatic space, especially in the scala tympani (Stöver et al., 1999; Yagi et al., 1999; Suzuki et al., 2000). It is possible, therefore, to transduce these cells with a gene encoding a secreted growth factor, which leads to overexpression and secretion of the transgenic protein into the perilymph, making it available to the SGCs. This strategy has been successfully used with Ad-GDNF to enhance survival of denervated SGCs (Yagi et al., 2001).

The goal of this experiment was to determine the combined effects of ES and virally mediated GDNF overexpression on the survival and health of SGCs in ototoxically deafened guinea pigs. The results demonstrate that the combined protection afforded by GDNF and ES is greater than that of either of the two alone.

\section{MATERIALS AND METHODS Animal groups}

Twenty-four pigmented guinea pigs (240-380 g) were used. Animals were obtained from an outbred colony (Elm Hill Breeding Labs, Chelmsford, MA). All animal experiments were approved by the University of Michigan Com- 
mittee for the Use and Care of Animals and were performed using accepted veterinary standards. The University of Michigan is fully accredited by the Association for Assessment and Accreditation of Laboratory Animal Care International.

Animals were divided into three treatment groups: ES alone $(\mathrm{N}=7)$, GDNF transgene delivered by adenoviral vectors $(\mathrm{Ad}-G D N F)$ alone $(\mathrm{N}=7)$, or $\mathrm{ES}+\operatorname{Ad}-G D N F(\mathrm{~N}=$ $8)$. The implant and the Ad-GDNF were placed in the left ear, whereas the right ear served as a control. In addition, two normal (nondeafened) guinea pigs were used in the immunocytochemistry experiments to detect GDNF in the cochlea. Ad-GDNF was administered in these animals as in the Ad-GDNF alone group.

On day 1, a combination of ototoxic drugs was systemically infused to eliminate most cochlear IHCs and OHCs bilaterally. On day 5 , deafening was verified with acoustically evoked auditory brainstem response audiometry (aABR), and then aseptic surgery was performed to place a cochlear implant electrode into the inner ear and/or inoculate the cochlea with adenovirus vector containing the human GDNF insert (Ad-GDNF). The recombinant adenovirus vector has been previously described (Lapchak et al., 1997). In animals that received ES, the stimulation started on day 8 following a baseline electrical ABR (eABR), to ensure electrode function, and continued for 36 days. All animals were euthanized on day 44 following eABR measurement to reconfirm electrode function.

\section{Acoustic ABRs}

Baseline and postdeafening (day 5) aABRs were performed on all subjects. Animals were anesthetized with xylazine $(10 \mathrm{mg} / \mathrm{kg} \mathrm{IM})$ and ketamine $\mathrm{HCl}(40 \mathrm{mg} / \mathrm{kg} \mathrm{IM})$ and placed in a soundproof room. Neural responses were recorded with subcutaneous recording needle electrodes placed at the vertex (active) against a reference placed at the midline of the skull approximately $2 \mathrm{~cm}$ anterior to bregma and in the thigh (ground). Computer-generated alternating polarity pulses (100 $\mu$ sec duration, $50 \mathrm{pps})$ were delivered to a transducer positioned in the ear canal. Clicks were calibrated with a Bruel and Kjaer condenser microphone relative to an SPL peak-to-peak equivalent. Stimulus-locked electrophysiological activity was averaged for 1,024 samples for $7.7 \mathrm{msec}$ following stimulation. Stimuli were provided at various intensities to determine threshold, which was defined as the lowest stimulus intensity that evoked at least a $0.2 \mu \mathrm{V}$ (peak-to-peak, with a latency of 1.6-3.2 msec) replicable waveform as previously described (Mitchell et al., 1997). Animals were required to have a baseline aABR threshold less than or equal to $50 \mathrm{~dB}$ and a postdeafening aABR threshold shift greater than or equal to $60 \mathrm{~dB}$ SPL.

\section{Electrically evoked ABRs}

Animals with electrodes were anesthetized for eABRs on days 8 and 44. Neural responses were recorded from epidural recording screws positioned at vertex (active), midline (reference), and ipsilateral to implant (ground). Two thousand forty-eight responses to 50 - $\mu$ sec computergenerated monophasic current pulses, presented at 50 pulses/second with an alternating polarity on each presentation, were averaged and analyzed in 5- $\mu \mathrm{A}$ steps near threshold. Threshold was determined by visual inspection of the responses and defined as the lowest intensity level at which a clear replicable waveform was visible in the evoked trace. For inclusion in this study, subjects were required to demonstrate thresholds of less than $100 \mu \mathrm{A}$ at the beginning and end of the stimulation period.

\section{Deafening procedure}

On day 1, animals were injected with a single dose of kanamycin (400 mg/kg SC). Two hours later, the animals were anesthetized as described above and prepared for cannulation of the jugular vein, as previously described (West et al., 1973), and infused with ethacrynic acid (EA; 40 or $50 \mathrm{mg} / \mathrm{kg} \mathrm{IV)}$. The temporal pattern of SGC degeneration and the density of SGCs in the normal guinea pig inner ear have previously been described (Jyung et al., 1989).

\section{Adenoviral vectors}

Replication-deficient recombinant adenoviruses were based on the human adenovirus serotype 5 from which three transcriptional regions (E1A, E1B, and a portion of E3) have been deleted (Lapchak et al., 1997). The vector contained the human GDNF gene driven by the cytomegalovirus (CMV) immediate promoter. Viral suspensions in $10 \%$ glycerol were kept at $-80^{\circ} \mathrm{C}$ until thawing for use.

\section{Viral administration and/or electrode implant procedure}

On day 5 , animals were anesthetized with ketamine and xylazine as described above. In addition, chloramphenicol sodium succinate $(30 \mathrm{mg} / \mathrm{kg}$ IM) was administered as a prophylactic antibiotic, and $0.5 \mathrm{ml}$ of $1 \%$ lidocaine $\mathrm{HCl}$ was injected SC for local anesthesia. The middle ear was exposed via the postauricular approach. Under an operating microscope, a small fenestra was made with a sharp probe in the otic capsule at the base of the cochlea. In the group that received Ad-GDNF, a $100-\mu l$ Hamilton syringe attached to a vinyl cannula with a fine polyimide tip was used to slowly inject $5 \mu \mathrm{l}$ of an isotonic adenoviral suspension (approximate concentration of $10^{10}$ adenoviral particles/ml in sterile normal Ringer's solution) into the scala tympani, as previously described (Prieskorn et al., 1999; Stöver et al., 1999). Ten minutes after inoculation, the cannula was removed, and the fenestra was covered with a small piece of fascia that adhered to the otic capsule. The bulla defect was sealed with carboxylate cement (Durelon ESPE America, Norristown, PA). Dexon adsorbable suture was used for the subcuticular closure, and the skin was closed with nylon sutures.

With respect to cochlear implants, prior to implantation, each stimulating electrode surface was activated to a stable minimal impedance value $(2-5 \mathrm{k} \Omega$ ) using cyclic voltometry ( -0.9 to $0.5 \mathrm{~V}$ ) for 30 minutes at $3 \mathrm{~Hz}$ (triangular wave) in saline. Epidural recording electrodes were placed at the vertex ( $1 \mathrm{~cm}$ posterior to bregma), midline ( 2 $\mathrm{cm}$ anterior to bregma), and ipsilateral to the parietal bone ( $1 \mathrm{~cm}$ lateral to bregma). A restraint bolt (to secure the portable stimulator) was fastened over bregma by three self-tapping screws. Methyl methacrylate was used to cement the recording electrodes, restraint bolt, and electrode base to the skull. Animals were implanted via the postauricular approach described above, with a single ball $(250 \mu \mathrm{m})$ electrode constructed from $90 \%$ platinum$10 \%$ iridium (Pt-Ir) wire (76 $\mu \mathrm{m}$ in diameter) inserted approximately $3 \mathrm{~mm}$ into the scala tympani through the round window membrane. In addition to the stimulating 
electrode, an uninsulated Pt-Ir return electrode $(130 \mu \mathrm{m})$ was placed in the middle ear. The ear was closed as described above (Mitchell et al., 1997). In the group of animals that received both Ad-GDNF and ES, the virus was injected first, followed by electrode implantation. To prevent leakage of inner ear fluid and viral suspension, the round window membrane was covered with fascia.

\section{ES}

On day 8, after eABR assessment, all implanted animals began continuous pulsatile ES via a wearable stimulator that was plugged into the electrode connector. The construction and performance details of this stimulator, custom made at the Kresge Hearing Research Institute, were previously described (Mitchell et al., 1997). Continuous stimulation $(100 \mu \mathrm{A}$ peak, $100 \mu \mathrm{sec} /$ phase, $250 \mathrm{~Hz})$ was provided for 36 days at a $40 \%$ duty cycle ( $400 \mu$ sec on, $600 \mu$ sec off). The parameters for ES were selected to accomplish optimal protection of the SGC population, as empirically determined in guinea pigs (Mitchell et al., 1997). These parameters also represent a typical on time for an average implant user among cochlear implant patients.

\section{Tissue processing and cell counting}

Forty-three days after deafening, after eABR measurement, the animals were deeply anesthetized, perfused intracardially with $2.5 \%$ glutaraldehyde, and decapitated. The temporal bones were removed for histological evaluation. Tissues were postfixed in $2.5 \%$ glutaraldehyde for 2-3 hours. To shorten the decalcification time, the otic capsule was trimmed, leaving the modiolar bony core with the attached spiral organ of Corti. Cochlear tissues were continuously agitated during the decalcification period (2 days in 1 liter of $4 \%$ EDTA with $0.25 \%$ glutaraldehyde). Tissues were then dehydrated in a series of increasing ethanol concentrations and embedded in JB-4 (Electron Microscopy Scientific, Washington, PA). Sections were obtained at a near-midmodiolar plane (1 $\mu \mathrm{m}$ thickness). Every thirtieth section was collected on a glass slide, stained with Paragon, and coverslipped with Permount (Fisher Scientific, Pittsburgh, PA).

In total 10 sections were collected from each cochlea. From these 10 sections, five slides were chosen randomly for counting and statistical analysis. If a low-quality (folds in the plastic) section was among those selected, it was replaced by another randomly selected section. In the guinea pig cochlea, midmodiolar sections include seven or eight regions of Rosenthal's canal (Fig. 1). Frequently, the upper Rosenthal's canals are inseparable. Therefore, the number of SGCs was assessed in six regions (A-F). All neurons with a discernible nucleus present in the section were counted. SGC density (SGC number/10,000 $\mu^{2}$ ) was calculated using a Meta-Morph computerized imageanalysis system (Yagi et al., 2001). The entire area of Rosenthal's canal in each counted section was circled for the purpose of area calculation (performed by the software). The boundaries of the canal were drawn at the interface between the bone and the soft tissue within Rosenthal's canal. After counting five sections of each cochlea, the average value of the SGC density was calculated for each cochlea. SGC density was analyzed using repeated-measures ANOVA, and post hoc paired comparisons were made with Newman-Keuls multiplecomparisons test. An unpaired Student's $t$-test was used

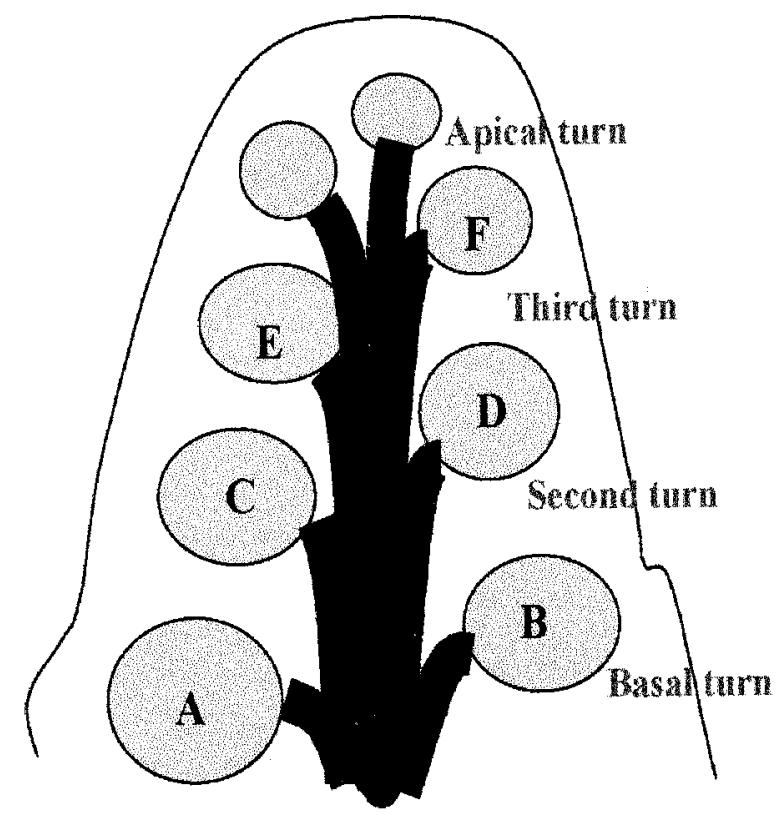

Fig. 1. Schematic drawing showing a midmodiolar cross section of the guinea pig cochlea as it was sectioned, depicting the regions of Rosenthal's canal used for SGC counts. The lower basal cochlear turn (high-frequency detection area) is in region $\mathrm{A}$ and the apical-most area (low-frequency detection) is in region $\mathrm{F}$.

to evaluate the statistical significance of differences between the right and the left ears of each of the groups. $P<$ 0.05 was considered significant.

\section{Immunohistochemistry}

To test the expression of Ad-GDNF and its ability to synthesize GDNF in the cochlea, we obtained frozen sections and performed immunocytochemistry using GDNFspecific antibodies on two normal animals inoculated with Ad-GDNF. Guinea pigs were deeply anesthetized and perfused with $4 \%$ paraformaldehyde in phosphate-buffered saline (PBS), pH 7.4, through the aorta. After removal of the temporal bones, inner ear tissues were immersed in fixative for 1 hour. The specimens were decalcified in $4 \%$ EDTA in PBS for 1 week and then immersed in $30 \%$ sucrose (in PBS) overnight. Samples were then placed in a vacuum for 30 minutes for embedding in OCT and frozen in ethanol and dry ice, as previously described (Whitlon et al., 2001). The frozen tissue blocks were sectioned at 10 $\mu \mathrm{m}$ using a Leica CM3000 cryostat. Sections were air dried for 2 hours, permeabilized in $0.3 \%$ Triton X-100 for 10 minutes, and then incubated in a polyclonal antiGDNF antibody (Santa Cruz Biotechnology, Santa Cruz, CA) for 60 minutes, rinsed in buffer, and incubated with rhodamine-conjugated goat anti-rabbit secondary antibody (Jackson Immunoresearch Laboratories, West Grove, PA) diluted 1:100 for 30 minutes. After a final rinse, sections were mounted on microscope slides with Crystal/Mount. The negative control was the right side (not inoculated with the Ad-GDNF). Samples were analyzed and photographed with a Leica DMRB epifluorescence microscope on Kodak Ektachrome 200 film. Adobe Photoshop software was used to generate figures. 

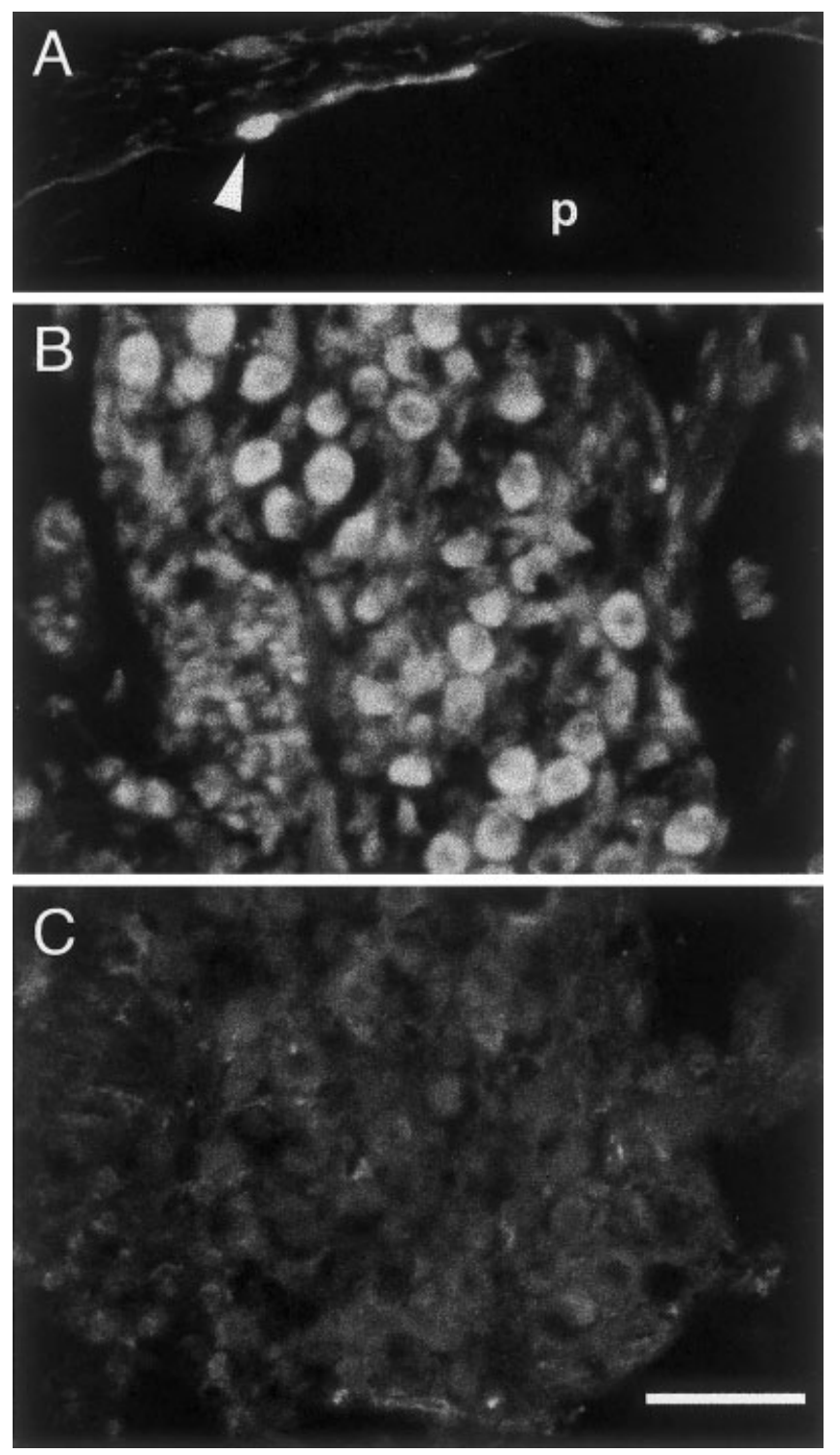

Fig. 2. Cryosections of the cochlea stained with a GDNF-specific antibody and viewed by immunofluorescence, showing the mesothelial cells (A) and the spiral ganglion (B) in a left ear inoculated with Ad-GDNF and the spiral ganglion of a control (right) ear (C). A: Mesothelial cells that line the perilymphatic fluid space (arrowhead) exhibit GDNF-specific immunolabeling (p). B: Within Rosenthal's canal, the cell bodies of SGCs are positive for GDNF antibody. C: Neurons are negative for GDNF. A small amount of immunoreactivity is detected in the Schwann cells surrounding SGCs. Scale bar $=100 \mu \mathrm{m}$.

\section{RESULTS \\ GDNF overexpression in Ad-GDNF-treated ears}

To determine the efficacy of Ad-GDNF inoculationmediated GDNF expression in the cochlea, vector-treated ears and control ears were prepared for immunocytochemistry with GDNF-specific antibodies. In inoculated ears, the mesothelial cells demonstrated strong positive immunofluorescence (Fig. 2A). SGCs were also positive for the GDNF antibody in the inoculated ear (Fig. 2B), whereas in
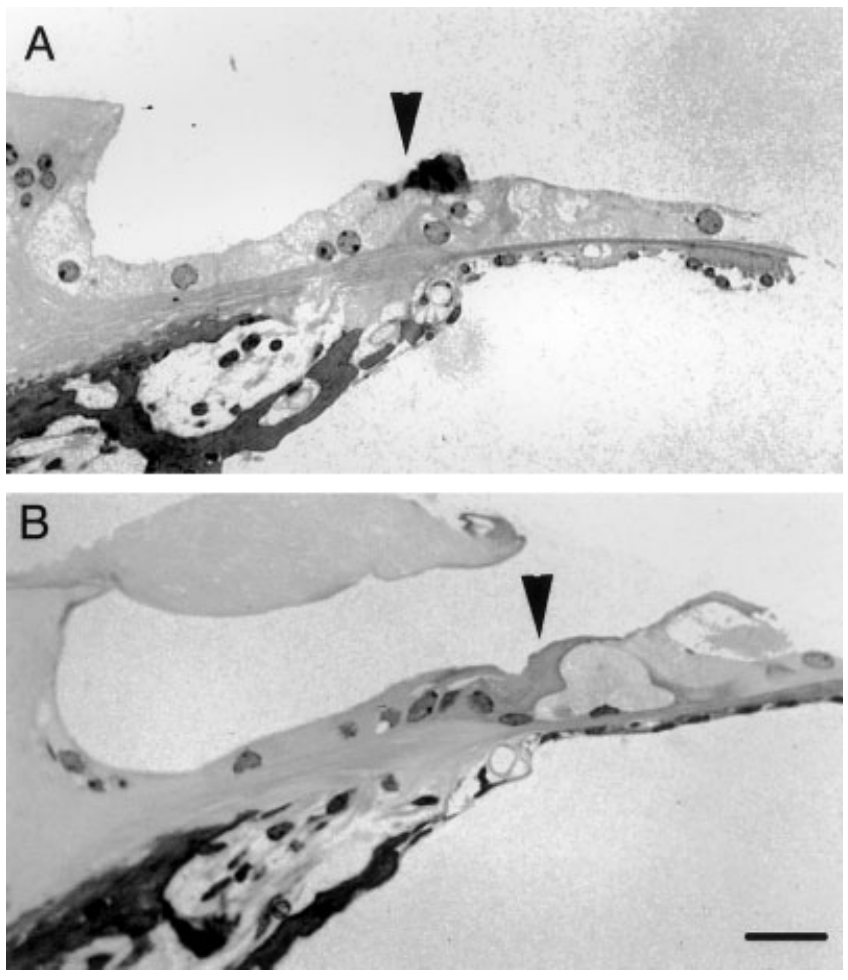

Fig. 3. Plastic sections of the organ of Corti in the basal turn of a cochlea from guinea pigs sacrificed 43 days after treatment with kanamycin and $40 \mathrm{mg}$ EA (A) or $50 \mathrm{mg}$ EA (B). In these animals, the entire populations of OHCs and IHCs are missing. In place of the hair cells, expanded supporting cells and scar tissue are detected. The presumed site where IHCs normally reside is denoted by the arrowhead. Scale bar $=25 \mu \mathrm{m}$.

control ears the level of staining in these cells was much lower (Fig. 2C). GDNF immunoreactivity in Figure 2 shows the basal cochlear turn (region B). SGCs and mesothelial cells in higher cochlear turns were also immunoreactive with the GDNF antibody (data not shown).

\section{Elimination of hair cells}

To mimic the sensorineural deafness caused by degeneration of the IHCs, it was necessary to eliminate these cells. A combination of kanamycin with EA was used, as previously described (West et al., 1973). Animals had to have a threshold shift from normal baseline greater than $60 \mathrm{~dB}$ measured by click-ABR to be included in the study. The cochlea of such animals typically has no surviving IHCs in the lower three turns (Fig. 3A,B). Occasional surviving IHC are seen in the apical turn, which was not used in counts for this study.

\section{eABRs}

eABR results demonstrate that the implants were functional in all subjects receiving ES. All animals had an eABR threshold of less than $100 \mu \mathrm{A}$ throughout the study. There was no significant difference in average eABR threshold between the ES and the GDNF/ES groups. On average, eABR thresholds decreased over the course of the study by approximately $10 \%$ (Table 1 ). 
TABLE 1. Mean eABR Thresholds in Microamperes ${ }^{1}$

\begin{tabular}{lcc}
\hline Treatment & Day 8 & Day 44 \\
\hline GDNF/ES & $53.8( \pm 22.0)$ & $49.4( \pm 13.8)$ \\
ES & $59.3( \pm 15.4)$ & $52.1( \pm 10.8)$
\end{tabular}

${ }^{1}$ Values in parentheses are SD. There are no significant differences between the two groups, GDNF/ES and ES. There are no differences between prestimulation (day 1) and poststimulation (day 44) measures.

\section{SGC survival in the ES group}

The influence of chronic ES and GDNF on the survival of SGC is illustrated in Figure 4. Across the cochlear turns, the density of SGCs in the treated ear was higher than that in the nontreated ear. This difference was significant at the $P<0.05$ level in regions A, B, and D (Fig. 4A). The better effect of ES to the region of the electrode (first turn) is consistent with the restricted spread of current expected at this stimulation level and was observed in our previous studies (Mitchell et al., 1997) as well as those from other laboratories (Leake et al., 1992).

\section{SGC survival in the GDNF group}

Ears inoculated with Ad-GDNF exhibited robust protection of the treated (left) ears compared with the control (right) ears. The protective influence of GDNF was significant $(P<0.05)$ in all cochlear turns (Fig. 4B). Although the significant protective effect was observed throughout the length of the cochlea, it was somewhat greater in the base, which is consistent with the previous finding of the density of distribution of viral vectors (Stöver et al., 1999).

\section{SGC survival in the combined GDNF/ES group}

In GDNF/ES-treated animals, the SGC survival was significantly greater in the treated vs. control ears throughout the cochlea (Fig. 4C).

\section{Comparison across groups}

Because the best effect of ES on nerve survival is noted in the basal areas of the cochlea (Fig. 5, regions A and B), it should be most illuminating to assay the relative effectiveness of the three treatments in regions $\mathrm{A}$ and $\mathrm{B}$ (combined). Figure 5 shows the SGC density in regions A and $\mathrm{B}$ in the three groups, ES alone, GDNF alone, and GDNF/ ES, and their contralateral nontreated control ears. There was little difference across the nontreated ears. However, the difference between the treated and nontreated (control) ears of each group was significant at the $P<.05$ level (Fig. 5). Treatment with GDNF + ES was significantly more effective than treatment with either factor alone, and GDNF alone was significantly more effective than ES alone.

\section{SG morphology in all groups}

With cross sections of the cochlea that are used for counting, it is also possible to evaluate the general morphological features of the SGCs. The micrographs in Figure 6 show representative sections from the basal turn (region B) of all four groups. The best preservation of number and morphological features of the neurons was seen in the GDNF/ES group (Fig. 6D). SGCs in control (deafened and nontreated) ears appeared shrunken, and the spaces between cells in Rosenthal's canal were larger than normal in control ears (Fig. 6A). SGCs in treated
A

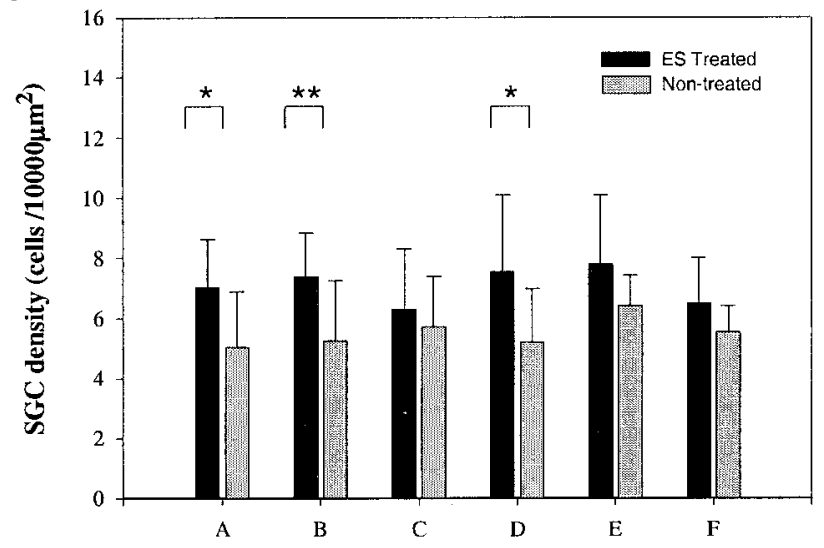

B

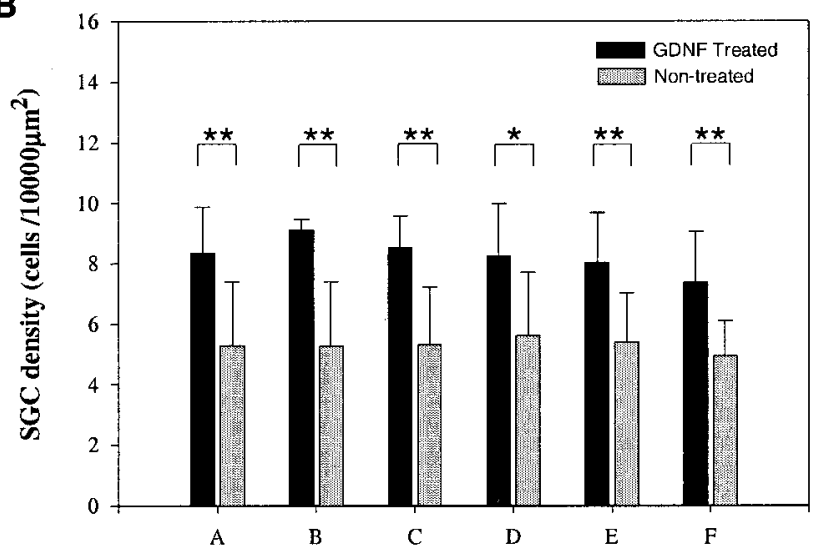

C

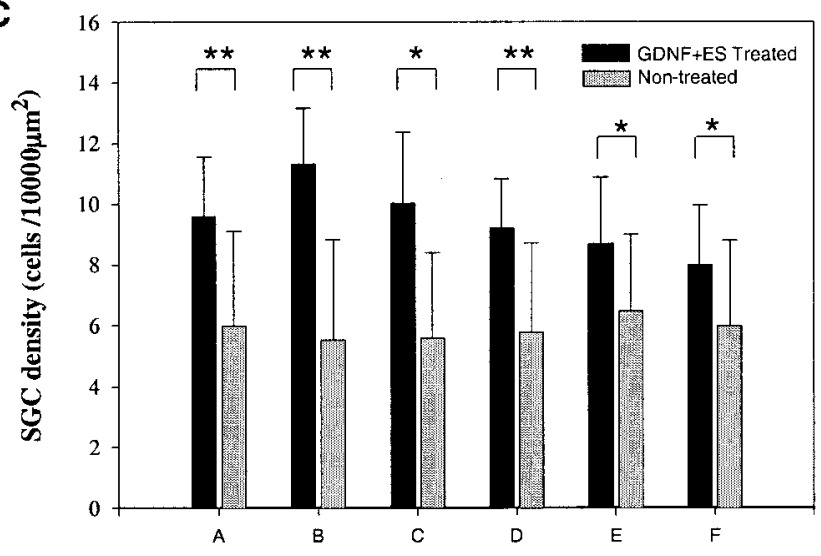

Fig. 4. Density of SGCs (mean \pm SD) in each cochlear region in the left (treated) and right (control) ears in the three experimental groups: ES group (A), GDNF group (B), and GDNF/ES group (C). A: The density of surviving SGCs in the treated ears is higher than that in nontreated ears throughout the counted regions. In regions A, $\mathrm{B}$, and $\mathrm{D}$, the differences are significant $(* P<0.05, * * P<0.01)$. B: The density of surviving SGCs is significantly higher in GDNFtreated vs. nontreated ears in all cochlear areas $(* P<0.05$, ** $P<$ 0.01). C: SGC density in the GDNF/ES-treated ears is significantly higher than the density in nontreated contralateral ears in all cochlear regions $(* P<0.05, * * P<0.01)$. 


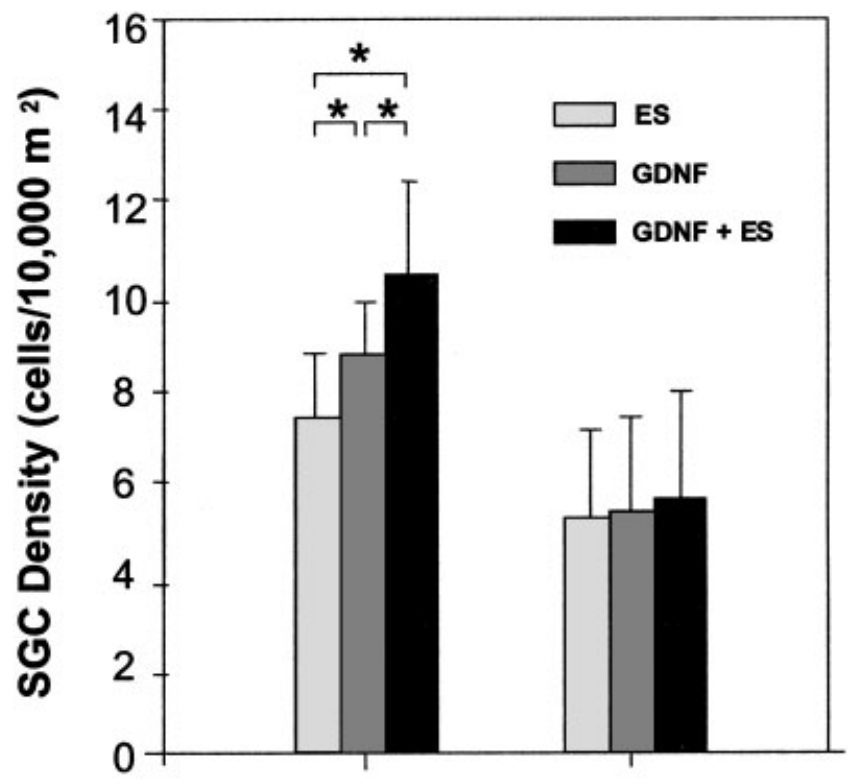

\section{Treated Non-treated ear}

Fig. 5. Histogram comparing SGC density in all three treatment groups: ES, GDNF, and GDNF/ES. There are significant differences between the GDNF/ES group and the ES group ( $* P<0.05)$. There are also differences between the GDNF group and the ES group $(* P<$ 0.05). There are no significant differences in nontreatment (right) ears among all three groups. Data are mean $\pm \mathrm{SD}$.
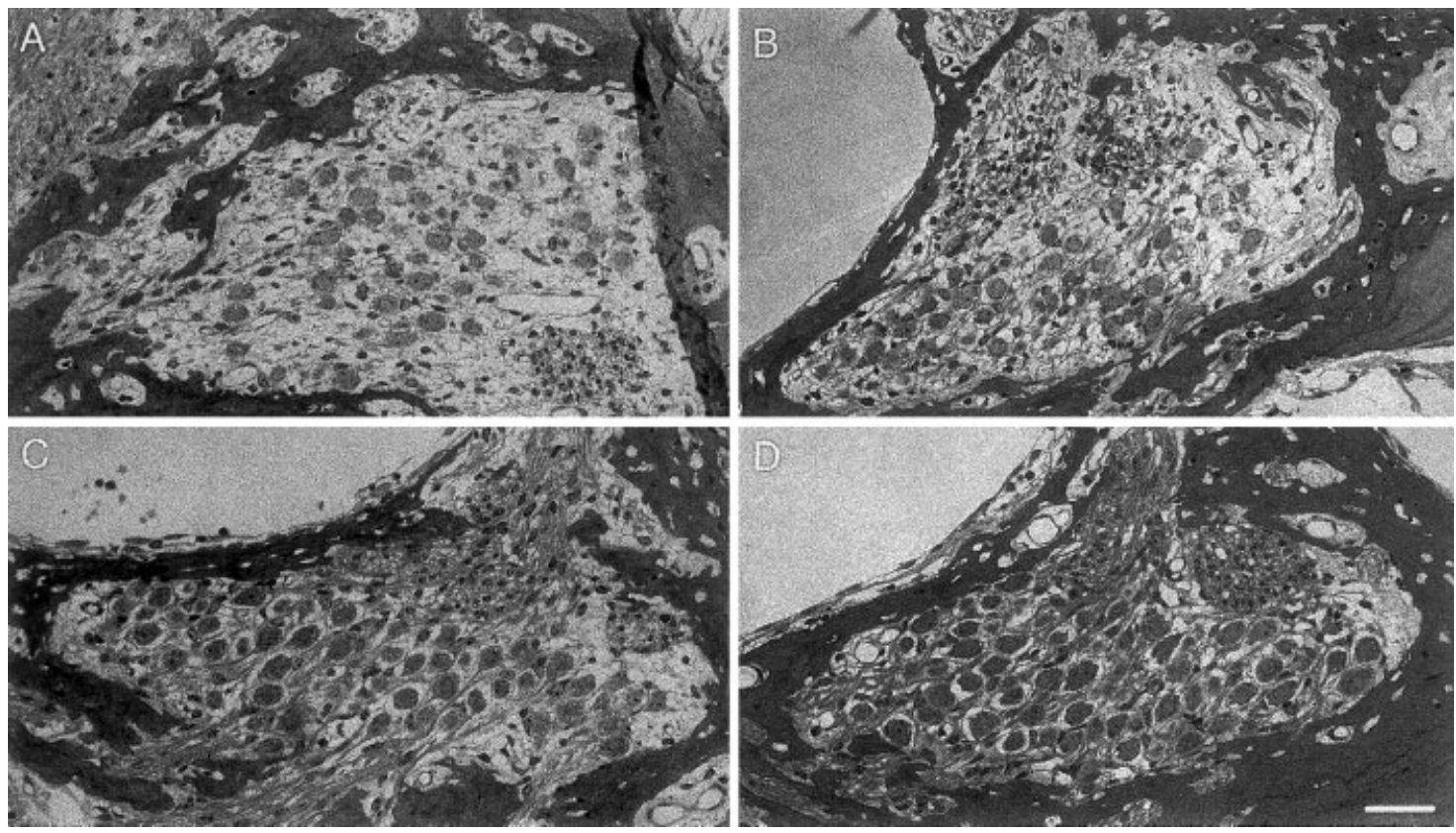

Fig. 6. Cross sections of Rosenthal's canal in ears receiving $40 \mathrm{mg}$ EA treatment. A: A control ear (deafened and nontreated) showing a severe depletion of the SGC population. Neuronal cell bodies are shrunken, leaving spaces between cells in Rosenthal's canal. B: SGCs in the ES group, with better morphological preservation and higher cell packing density than the control group. C: Representative ear groups (Fig. 6B-D) appeared to have a larger diameter than the control cells. There were also smaller spaces between cells in the treated groups. The GDNF/ES group exhibited the largest cells among the different groups. No differences in nuclear morphology were noted among the four groups. In animals that received GDNF treatment, the myelin was more prominent, allowing the distinction of nerve fibers (Fig. 6C,D).

\section{DISCUSSION}

Our findings confirm those of previous studies showing that both ES and GDNF can enhance SGC survival following deafness when applied singly. They also provide evidence of a synergy in these effects, with increased SGC survival when ES and GDNF are applied together. This raises interesting questions about the underlying mechanisms as well as suggesting new avenues for clinical interventions.

\section{Mechanism of action of GDNF in SGCs}

The mechanism of GDNF action in the inner ear is not well understood. GDNF binds to two receptors. It initially binds to a glycosyl phosphatidyl inositol (GPI)-linked receptor, GFR $\alpha$ (Durbec et al., 1996; Jing et al., 1996; Treanor et al., 1996). Once bound, the complex then binds to the transmembrane tyrosine kinase Ret receptor. In the cytoplasm, the activated receptor complex induces the PI3K/Akt and ERK pathways, which have been shown to play a role in cell survival (Pong et al., 1998; Mograbi et al., 2001). In addition, GDNF activates the transcription factor CREB (Feng et al., 1999; Poteryaev et al., 1999; treated with GDNF demonstrates a well-preserved SGC population with normal morphological appearance. No spaces are observed in Rosenthal's canal. Nerve fibers (myelin) can be identified. D: A nearly normal complement and morphology of SGCs is seen in the combinedtreatment group. Scale bar $=25 \mu \mathrm{m}$. 
Hayashi et al., 2000). GDNF promotes a rapid phosphorylation of mitogen-associated protein kinase and CREB in dopaminergic neurons. CREB may regulate transcription of $b c l-2$, which suppresses apoptosis and promotes neuronal survival (Finkbeiner and Greenberg, 1998). GDNF has also been reported to enhance axonal regeneration via a cAMP-dependent mechanism (Cai et al., 1999) and to protect dopaminergic neurons by activating the antioxidant enzyme systems (Chao and Lee, 1999).

GDNF mRNAs have been detected in the developing OHCs and IHCs, and in the mature IHCs (Ylikoski et al., 1998). In addition, GFR $\alpha 1$ has been detected in SGCs and in their Schwann cells during development and in adult animals. GDNF, GFR $\alpha 1$, and c-ret mRNA are expressed in the modiolus (Stöver et al., 2000). The level of Ret expression in the normal inner ear was rather low; however, GDNF was clearly identified in SGCs following overexpression with Ad-GDNF. Furthermore, it is likely that the stress associated with ototoxic ablation of hair cells leads to up-regulation of GDNF (Nam et al., 2000). Additional pathways or receptors (e.g., GFR $\alpha 2$, to which GDNF binds with lower affinity) may potentially be involved in the activity of GDNF in SGCs. Further experiments will be necessary to determine the signaling pathway(s) of GDNF that protects the SGCs.

Interaction between two or more neurotrophic factors is also likely to influence the SGCs. For example, it has been shown that the protective effect of GDNF on axotomized corticospinal CNS neurons depends on the presence of BDNF (Giehl et al., 1998). It is therefore possible that GDNF may influence the SGCs indirectly, via upregulation of BDNF expression or other neurotrophic factors, which, in turn, act on these cells in an autocrine fashion. Moreover, though it has not yet been shown for GDNF, BDNF may act as a neurotransmitter and influence spontaneous activity of neurons, including SGCs (Levine et al., 1995; Li et al., 1998a,b).

\section{Mechanism of ES-mediated SGC protection}

The positive influence of ES on SGC survival has been demonstrated in kittens and guinea pigs (Hartshorn et al., 1991; Leake et al., 1991; Mitchell et al., 1997). Several pathways for protection resulting from depolarization are possible, and one or more may be involved in the effects of ES in the cochlea. These pathways include: 1 ) regulation of $\mathrm{Ca}^{2+}$ via L-type voltage-gated $\mathrm{Ca}^{2+}$ channel; 2) an autocrine neurotrophin loop; 3) cAMP production; and 4) CAM kinase-mediated phosphorylation of CREB, with subsequent changes in gene expression (Hansen et al., 2001). In SGC cultures, depolarization elevates cAMP and results in SGC protection (Hansen et al., 2001). In vivo experiments have demonstrated that BDNF expression in SGCs is constitutive and is not increased by electrical activation (Zha et al., 2001). The influence of ES on expression of GDNF in vivo is not well characterized. However, the Akt and ERK signaling pathways do not play a major role in supporting SGC survival by depolarization (Hansen et al., 2001).

Several reports suggest that electrical activity elevates $\mathrm{Ca}^{2+}$ concentration, leading to an increase in intracellular elevation of cAMP, resulting in neuronal extension (Ming et al., 2001). SGC protection with ES is mediated by the L-type voltage-gated $\mathrm{Ca}^{2+}$ channel in vitro (Hegarty et al., 1997) and in vivo (Miller, 2001). In vitro, the protective effects of depolarization require the presence of extracel- lular $\mathrm{Ca}^{2+}$ during stimulation as well as functional L-type $\mathrm{Ca}^{2+}$ channels and appear to be mediated by elevation of cytoplasmic $\mathrm{Ca}^{2+}$ (Hegarty et al., 1997).

Several variable parameters in the ES determine the extent of the protective influence on SGCs. Among these parameters are the frequency of stimulation, the amount of current delivered, and the duty cycle (percentage time on or off). Comparative studies helped determine optimal stimulation parameters in kittens (Leake et al., 1991) and in guinea pigs (Mitchell et al., 1997). The parameters used for ES in these studies are identical to the optimal stimulation determined in guinea pigs (Mitchell et al., 1997). However, the strain of guinea pigs used here (Elm Hill) was different from the Murphy animals used in the Mitchell et al. study. This may explain the slight differences in protection observed in the ES alone group. In addition, animals in the present study were stimulated for 1 week less than those in the Mitchell et al. study. Nevertheless, the ES parameters are likely to be at or near optimal levels, resulting in a "saturated" effect on SGC survival.

\section{Mechanism of the enhanced SGC protection by combined GDNF and ES treatment}

Augmentation of the protective effects of depolarization by neurotrophic factors has been demonstrated in SGCs in vitro (Hegarty et al., 1997). Our study provides the first set of data on the combined effects of ES and growth factor overexpression in SGC in vivo. The data confirm the findings obtained in vitro and demonstrate that combined treatment (GDNF/ES) significantly enhances SGC survival in deafferented ears. One important question is whether GDNF and ES exert their protective effects via a common signaling pathway. Insofar as we selected electrical stimulation parameters that are optimal (at or near saturation) for SGC survival, the augmented protection afforded by GDNF, when compared with the individual effects of GDNF or ES alone, indicates that GDNF and ES use somewhat independent pathways in exerting their protection.

In this study, ES-mediated SGC protection was greatest in the basal turn, which is consistent with previous work from our laboratory (Mitchell et al., 1997) and that of others (Leake et al., 1991). Although GDNF's protective effects covered a larger portion of the cochlea, its greatest protective effects were in the basal cochlea. These observations likely reflect the distribution of the applied protective factors along the length of the cochlear duct. The greater apical extent of protection for GDNF relative to ES probably is due to diffusion of the GDNF protein from its site of production in the mesothelial cells of the basal turn into perilymph at higher cochlear turns or takes place via the fluid bathing the SGCs in the modiolus. Deeper insertion of the stimulating electrode into the guinea pig cochlea would likely shift the region of enhanced protection by ES more apically.

Combining the implantation surgery with inoculation of the vector presents a technical challenge. The main possible complication is leakage of the viral vector from the opening in the round window used for inserting the electrode. This problem may account for the greater apical extent of GDNF's protective effects when applied alone, compared with the combination group. In the future, alternative approaches for inoculation or staggered inoculation-implantation may further enhance the protective effect of the combined intervention. 
Our data suggest that GDNF overexpression combined with ES therapy has a greater influence on SGC survival than does either single treatment. Based on the saturation of the protection by ES alone, we suggest that a nonoverlapping mechanism underlies the influence of ES and GDNF. However, a partially overlapping mechanism cannot be ruled out. Based on in vitro experiments with cultured SGC, the mechanisms for the protective effects of neurotrophic factors and membrane depolarization are additive. Depolarization influences neuronal survival in these cultures via a mechanism that involves $\mathrm{Ca}^{2+}$ entry into the cells via L-type $\mathrm{Ca}^{2+}$ channels (Hansen et al., 2001). The increase in $\mathrm{Ca}^{2+}$ activates CAM-kinase, leading to cell survival. The elevation of intracellular $\mathrm{Ca}^{2+}$ may also activate growth factors, which act in an autocrine loop and bind to Trk receptors that stimulate cell survival signals through PI3 pathways. One way by which ES may increase the responsiveness of SGCs to growth factors is by enhancing recruitment of growth factor receptors to the cell surface, as demonstrated in other systems (Meyer-Franke et al., 1998; Reiriz et al., 2002).

The possibility that ES can directly promote GDNF secretion should also be considered. Although no data are available to support or refute this possibility in the inner ear, data obtained in other systems suggest that depolarization of the cell membrane increases GFR $\alpha 1$ and $-\alpha 2$ GDNF receptor expression during development (Doxakis et al., 2000). Several neurotrophic factors have been reported to prevent synaptic fatigue caused by ES (Munson and McMahon, 1997; Gottschalk et al., 1998). Thus, it is possible that GDNF may contribute to prevention of fatigue in SGCs.

\section{Effects on myelin}

After a deafening by kanamycin and EA, surviving SGCs have little or no perikaryal myelin. The findings show that overexpression of GDNF is correlated with enhanced preservation of the myelin around the SGCs. This suggests that GDNF may have an effect on the Schwann cells and their ability to maintain the myelin sheath around the neurons. This in turn may help to preserve the structure and function of SGCs. If true, this finding raises the possibility that the influence of GDNF on SGCs is, at least in part, mediated indirectly via the Schwann cells in Rosenthal's canal.

\section{GDNF distribution following Ad-GDNF treatment}

Previous studies have shown that the cells most efficiently transduced by the adenoviral vector are the mesothelial cells lining the perilymphatic fluid spaces. In this study, we demonstrated that these cells produce high levels of GDNF. Our observations of markedly enhanced SGC survival indicate that, in Ad-GDNF-transduced ears, there was an increased GDNF protein level resulting from secretion by mesothelial cells into the perilymph. The high level of GDNF staining in the SGCs indicates that the protein is internalized after it binds to receptors on these neurons. The presence of GDNF receptors in the modiolus has been demonstrated previously (Stöver et al., 2000). Thus, the influence of GDNF on SGC survival may be via a paracrine mechanism. The level of GDNF protein immunoreactivity qualitatively appeared to be similar throughout the cochlear spiral. This is consistent with the results showing GDNF protection in all cochlear turns. The effi- ciency of gene expression in the basal cochlea is higher, based on results of experiments using reporter genes, than in other turns following introduction of the vector into the scala tympani of the basal turn (Stöver et al., 1999; Yagi et al., 1999). This may explain the enhanced protection observed in the basal turn compared with the upper turns of the cochlea. In the contralateral (nontreated) side, only trace GDNF expression was found. This low level of expression most likely represents the typical low-level endogenous expression of these molecules in the mature inner ear (Nam et al., 2000).

\section{Relationship between eABR thresholds and SGC density}

Several factors influence the physiology of the denervated SGC and the performance of cochlear implants. In the absence of SGCs, electrically evoked action potential in the ascending auditory pathways cannot be generated with a cochlear implant. However, with a reasonable survival of ganglion cells, the density of remaining SGCs has not always correlated well with the performance of the cochlear implant (Hall, 1990; Incesulu and Nadol, 1998). Therefore, although preserving as many SGCs as possible is certainly an important goal in enhancing cochlear implant function, it cannot be assumed that the performance of the SGCs directly correlates with the density. In fact, our data show a lack of significant difference between the GDNF/ES group and the GDNF group in eABR thresholds, despite the significant difference in SGC density between these groups. It is likely that additional growth factors or other gene products further enhance the physiology of the remaining SGCs.

\section{Gene vs. protein therapy}

There are two major ways to introduce a therapeutic protein (such as a neurotrophic factor) into the inner ear. One is to infuse the protein itself, and the other is to introduce a transgene that will promote synthesis of the protein. Each method has several advantages and disadvantages. The main advantage of infusing the protein itself is the ability to regulate the amount (and therefore concentration) of the protein in the inner ear fluid and, depending on the delivery system, to start and stop it at will. However, unbound protein has the potential for immunogenicity and rapid degradation by proteases. Furthermore, although the duration of delivery can be controlled, logistically delivery cannot be provided indefinitely, though prolonged infusions are possible using osmotic pumps. The use of gene therapy involves the introduction of the gene into cells that are then expected to secrete the gene product. The main advantage of this method is the continuous production and secretion of the protein over a period of weeks and perhaps months. As vectors that shuttle genes into tissues improve, it may also become possible to regulate the level of gene expression by using dietetically regulated promoters. Although the use of viral vectors involves the risk of cytotoxicity or immune response, future vectors will, it is hoped, benefit from improved technology that will eliminate these problems.

\section{Implication of combined therapy in clinical use}

In addition to the insight that they provide regarding the mechanism of action of ES and GDNF on SGC sur- 
vival, these data are also important from a clinical standpoint. The cochlear implant can provide significant benefits to people with profound hearing impairment. However, there is great variability in clinical outcome, and, even with the best outcome, there is clearly room for improvement in the quality of hearing. Several factors influence the degree of success of the cochlear implant procedure, presumably including the number of surviving SGCs and the health (responsiveness) of the surviving SGCs. The ability to influence SGC survival and health can influence the benefits of the cochlear implant. The evidence from our study that combined intervention with ES and neurotrophic factors will further enhance the survival of SGCs raises at least three important challenges for eventual clinical intervention. First, it will be important to determine optimal conditions for ES in combination with neurotrophic factors. Second, it will be important to test other neurotrophic factors, which have been shown to enhance SGC survival following deafness, such as BDNF and NT-3, in combination with ES. Finally, it will be important to determine the best method of neurotrophic factor application and the technical feasibility of combining electrical cochlear implantation with growth factor therapy. The use of miniosmotic pumps to infuse protein, in addition to the insertion of the electrode into the inner ear, may pose a technical challenge and may be a source of additional risk for cochlear implant recipients. Alternative methods involving ex vivo gene transfer combined with the cochlear implant may prove to be less risky and more efficient. Finally, it is reasonable to suggest that these findings of an additive effect of ES and GDNF in promoting survival of deafferented auditory nerve cells likely also apply to deafferented neurons in other parts of the nervous system. If this is so, these findings have important implications for our understanding and potential treatment of neuronal cell death from neurodegenerative disease, neuronal stress, and perhaps aging in the nervous system.

\section{ACKNOWLEDGMENTS}

Alice Mitchell, Jong-Seung Kim, and Kathy Welch provided excellent assistance with data analysis; Chris Ellinger designed and manufactured the stimulators; and Amy Miller read the article critically and provided helpful suggestions.

\section{LITERATURE CITED}

Araki S, Kawano A, Seldon L, Shepherd RK, Funasaka S, Clark GM. 1998 Effects of chronic electrical stimulation on spiral ganglion neuron survival and size in deafened kittens. Laryngoscope 108:687-695.

Barkats M, Bilang-Bleuel A, Buc-Caron MH, Castel-Barthe MN, Corti O, Finiels F, Horellou P, Revah F, Sabate O, Mallet J. 1998. Adenovirus in the brain: recent advances of gene therapy for neurodegenerative diseases. Progr Neurobiol 55:333-341.

Bohne BA, Harding GW. 1993. Combined organ of Corti/modiolus technique for preparing mammalian cochleas for quantitative microscopy. Hear Res 71:114-124.

Buj-Bello A, Adu J, Pinon LG, Horton A, Thompson J, Rosenthal A Chinchetru M, Buchman VL, Davies AM. 1997. Neurturin responsiveness requires a GPI-linked receptor and the Ret receptor tyrosine kinase. Nature 387:721-724.

Cai D, Shen Y, De Bellard M, Tang S, Filbin MT. 1999. Prior exposure to neurotrophins blocks inhibition of axonal regeneration by MAG and myelin via a cAMP-dependent mechanism. Neuron 22:89-101.

Chao CC, Lee EH. 1999. Neuroprotective mechanism of glial cell line- derived neurotrophic factor on dopamine neurons: role of antioxidation. Neuropharmacology 38:913-916.

Doxakis E, Wyatt S, Davies AM. 2000. Depolarisation causes reciprocal changes in GFR(alpha)-1 and GFR(alpha)-2 receptor expression and shifts responsiveness to GDNF and neurturin in developing neurons. Development 127:1477-1487.

Durbec P, Marcos-Gutierrez CV, Kilkenny C, Grigoriou M, Wartiowaara K Suvanto P, Smith D, Ponder B, Costantini F, Saarma M, Sariola H, Pachnis V. 1996. GDNF signalling through the Ret receptor tyrosine kinase. Nature 381:789-793.

Ernfors P, Duan ML, ElShamy WM, Canlon B. 1996. Protection of auditory neurons from aminoglycoside toxicity by neurotrophin-3. Nature Med $2: 463-467$.

Feng L, Wang CY, Jiang H, Oho C, Mizuno K, Dugich-Djordjevic M, Lu B. 1999. Differential effects of GDNF and BDNF on cultured ventral mesencephalic neurons. Brain Res Mol Brain Res 66:62-70.

Finkbeiner S, Greenberg ME. 1998. $\mathrm{Ca}^{2+}$ channel-regulated neuronal gene expression. J Neurobiol 37:171-189.

Giehl KM, Schutte A, Mestres P, Yan Q. 1998. The survival-promoting effect of glial cell line-derived neurotrophic factor on axotomized corticospinal neurons in vivo is mediated by an endogenous brain-derived neurotrophic factor mechanism. J Neurosci 18:7351-7360.

Gottschalk W, Pozzo-Miller LD, Figurov A, Lu B. 1998. Presynaptic modulation of synaptic transmission and plasticity by brain-derived neurotrophic factor in the developing hippocampus. J Neurosci 18:68306839.

Hall RD. 1990. Estimation of surviving spiral ganglion cells in the deaf rat using the electrically evoked auditory brainstem response. Hear Res 49:155-168.

Hansen MR, Zha XM, Bok J, Green SH. 2001. Multiple distinct signal pathways, including an autocrine neurotrophic mechanism, contribute to the survival-promoting effect of depolarization on spiral ganglion neurons in vitro. J Neurosci 21:2256-2267.

Hartshorn DO, Miller JM, Altschuler RA. 1991. Protective effect of electrical stimulation in the deafened guinea pig cochlea. Otolaryngol Head Neck Surg 104:311-319.

Hayashi H, Ichihara M, Iwashita T, Murakami H, Shimono Y, Kawai K Kurokawa K, Murakumo Y, Imai T, Funahashi H, Nakao A, Takahashi M. 2000. Characterization of intracellular signals via tyrosine 1062 in RET activated by glial cell line-derived neurotrophic factor. Oncogene 19:4469-4475.

Hegarty JL, Kay AR, Green SH. 1997. Trophic support of cultured spiral ganglion neurons by depolarization exceeds and is additive with that by neurotrophins or cAMP and requires elevation of $\left[\mathrm{Ca}^{2+}\right]_{i}$ within a set range. J Neurosci 17:1959-1970.

Henderson CE, Phillips HS, Pollock RA, Davies AM, Lemeulle C, Armanini M, Simmons L, Moffet B, Vandlen RA, Simpson LC, Moffet B, Vandlen RA, Koliatsos VE, Rosenthal A. 1994. GDNF: a potent survival factor for motoneurons present in peripheral nerve and muscle. Science 266: 1062-1064.

Incesulu A, Nadol JB Jr. 1998. Correlation of acoustic threshold measures and spiral ganglion cell survival in severe to profound sensorineural hearing loss: implications for cochlear implantation. Ann Otol Rhinol Laryngol 107:906-911.

Jing S, Wen D, Yu Y, Holst PL, Luo Y, Fang M, Tamir R, Antonio L, Hu Z Cupples R, Louis JC, Hu S, Altrock BW, Fox GM. 1996. GDNF-induced activation of the ret protein tyrosine kinase is mediated by GDNFR alpha, a novel receptor for GDNF. Cell 85:1113-1124.

Jyung RW, Miller JM, Cannon SC. 1989. Evaluation of eighth nerve integrity by the electrically evoked middle latency response. Otolaryngol Head Neck Surg 101:670-682.

Lapchak PA, Araujo DM, Hilt DC, Sheng J, Jiao S. 1997. Adenoviral vector-mediated GDNF gene therapy in a rodent lesion model of late stage Parkinson's disease. Brain Res 777:153-160.

Leake PA, Hradek GT, Rebscher SJ, Snyder RL. 1991. Chronic intracochlear electrical stimulation induces selective survival of spiral ganglion neurons in neonatally deafened cats. Hear Res 54:251-271.

Leake PA, Snyder RL, Hradek GT, Rebscher SJ. 1992. Chronic intracochlear electrical stimulation in neonatally deafened cats: effects of intensity and stimulating electrode location. Hear Res 64:99-117.

Levine ES, Dreyfus CF, Black IB, Plummer MR. 1995. Brain-derived neurotrophic factor rapidly enhances synaptic transmission in hippocampal neurons via postsynaptic tyrosine kinase receptors. Proc Natl Acad Sci USA 92:8074-8077. 
Li L, Parkins CW, Webster DB. 1999. Does electrical stimulation of deaf cochleae prevent spiral ganglion degeneration? Hear Res 133:27-39.

Li YX, Xu Y, Ju D, Lester HA, Davidson N, Schuman EM. 1998a. Expression of a dominant negative TrkB receptor, T1, reveals a requirement for presynaptic signaling in BDNF-induced synaptic potentiation in cultured hippocampal neurons. Proc Natl Acad Sci USA 95:1088410889.

Li YX, Zhang Y, Lester HA, Schuman EM, Davidson N. 1998b. Enhancement of neurotransmitter release induced by brain-derived neurotrophic factor in cultured hippocampal neurons. J Neurosci 18:1023110240.

Lin LF, Doherty DH, Lile JD, Bektesh S, Collins F. 1993. GDNF: a glial cell line-derived neurotrophic factor for midbrain dopaminergic neurons. Science 260:1130-1132.

Lin LF, Zhang TJ, Collins F, Armes LG. 1994. Purification and initial characterization of rat B49 glial cell line-derived neurotrophic factor. J Neurochem 63:758-768.

Lousteau RJ. 1987. Increased spiral ganglion cell survival in electrically stimulated, deafened guinea pig cochleae. Laryngoscope 97:836-842.

Manabe Y, Nagano I, Gazi MS, Murakami T, Shiote M, Shoji M, Kitagawa H, Setoguchi Y, Abe K. 2002. Adenovirus-mediated gene transfer of glial cell line-derived neurotrophic factor prevents motor neuron loss of transgenic model mice for amyotrophic lateral sclerosis. Apoptosis 7:329-334.

Meyer-Franke A, Wilkinson GA, Kruttgen A, Hu M, Munro E, Hanson MG Jr, Reichardt LF, Barres BA. 1998. Depolarization and cAMP elevation rapidly recruit TrkB to the plasma membrane of CNS neurons. Neuron 21:681-693.

Miller AL. 2001. Effects of chronic stimulation on auditory nerve survival in ototoxically deafened animals. Hear Res 151:1-14.

Miller JM, Chi DH, O’Keeffe LJ, Kruszka P, Raphael Y, Altschuler RA. 1997. Neurotrophins can enhance spiral ganglion cell survival after inner hair cell loss. Int J Dev Neurosci 15:631-643.

Ming G, Henley J, Tessier-Lavigne M, Song H, Poo M. 2001. Electrical activity modulates growth cone guidance by diffusible factors. Neuron 29:441-452.

Mitchell A, Miller JM, Finger PA, Heller JW, Raphael Y, Altschuler RA. 1997. Effects of chronic high-rate electrical stimulation on the cochlea and eighth nerve in the deafened guinea pig. Hear Res 105:30-43.

Mograbi B, Bocciardi R, Bourget I, Busca R, Rochet N, Farahi-Far D, Juhel T, Rossi B. 2001. GDNF-stimulated PI3K and Akt activities exert opposing effects on the ERK pathway. Importance for the rescue of neuroectodermic cells. J Biol Chem 4:4.

Moore MW, Klein RD, Farinas I, Sauer H, Armanini M, Phillips H, Reichardt LF, Ryan AM, Carver-Moore K, Rosenthal A. 1996. Renal and neuronal abnormalities in mice lacking GDNF. Nature 382:76-79.

Mou K, Hunsberger CL, Cleary JM, Davis RL. 1997. Synergistic effects of BDNF and NT-3 on postnatal spiral ganglion neurons. J Comp Neurol 386:529-539.

Mou K, Adamson CL, Davis RL. 1998. Time-dependence and cell-type specificity of synergistic neurotrophin actions on spiral ganglion neurons. J Comp Neurol 402:129-139.

Munson JB, McMahon SB. 1997. Effects of GDNF on axotomized sensory and motor neurons in adult rats. Eur J Neurosci 9:1126-1129.

Nadol JJ, Hsu W. 1991. Histopathologic correlation of spiral ganglion cell count and new bone formation in the cochlea following meningogenic labyrinthitis and deafness. Ann Otol Rhinol Laryngol 100:712-716.

Nam YJ, Stöver T, Hartman SS, Altschuler RA. 2000. Upregulation of glial cell line-derived neurotrophic factor (GDNF) in the rat cochlea following noise. Hear Res 146:1-6.

Otte J, Schunknecht HF, Kerr AG. 1978. Ganglion cell populations in normal and pathological human cochleae. Implications for cochlear implantation. Laryngoscope 88:1231-1246.

Pichel JG, Shen L, Sheng HZ, Granholm AC, Drago J, Grinberg A, Lee EJ, Huang SP, Saarma M, Hoffer BJ, Sariola H, Westphal H. 1996. Defects in enteric innervation and kidney development in mice lacking GDNF. Nature 382:73-76.

Pong K, Xu RY, Baron WF, Louis JC, Beck KD. 1998. Inhibition of phosphatidylinositol 3-kinase activity blocks cellular differentiation mediated by glial cell line-derived neurotrophic factor in dopaminergic neurons. J Neurochem 71:1912-1919.

Poteryaev D, Titievsky A, Sun YF, Thomas-Crusells J, Lindahl M, Billaud M, Arumae U, Saarma M. 1999. GDNF triggers a novel retindependent Src kinase family-coupled signaling via a GPI-linked GDNF receptor alpha1. FEBS Lett 463:63-66.
Prieskorn D, Dootz G, Yagi M, Miller JM, Dolan DF, Raphael Y. 1999. GDNF gene therapy against acoustic trauma in guinea pigs. Midwinter Meeting of the Association for Research in Otolaryngology, St. Petersburg Beach, Florida.

Reiriz J, Holm PC, Alberch J, Arenas E. 2002. BMP-2 and cAMP elevation confer locus coeruleus neurons responsiveness to multiple neurotrophic factors. J Neurobiol 50:291-304.

Sanchez MP, Silos-Santiago I, Frisen J, He B, Lira SA, Barbacid M. 1996. Renal agenesis and the absence of enteric neurons in mice lacking GDNF. Nature 382:70-73.

Schmeer C, Straten G, Kugler S, Gravel C, Bahr M, Isenmann S. 2002. Dose-dependent rescue of axotomized rat retinal ganglion cells by adenovirus-mediated expression of glial cell-line derived neurotrophic factor in vivo. Eur J Neurosci 15:637-643.

Shepherd RK, Clark GM, Black RC. 1983. Chronic electrical stimulation of the auditory nerve in cats. Physiological and histopathological results. Acta Otolaryngol 399(Suppl):19-31.

Shepherd RK, Matsushima J, Martin RL, Clark GM. 1994. Cochlear pathology following chronic electrical stimulation of the auditory nerve: II. Deafened kittens. Hear Res 81:150-166

Springer J, Kitzman P. 1998. Neuroprotective strategies involoving the neurotrophins and their signaling pathways. In: Mattson M, editor. Neuroprotective signal transduction. Totowa, NJ: Humana Press Inc. p 1-21.

Staecker H, Kopke R, Malgrange B, Lefebvre P, Van de Water TR. 1996. NT-3 and/or BDNF therapy prevents loss of auditory neurons following loss of hair cells. Neuroreport 7:889-894.

Stöver T, Yagi M, Raphael Y. 1999. Cochlear gene transfer: round window versus cochleostomy inoculation. Hear Res 136:124-130.

Stöver T, Gong TL, Cho Y, Altschuler RA, Lomax MI. 2000. Expression of the GDNF family members and their receptors in the mature rat cochlea. Brain Res Mol Brain Res 76:25-35.

Stöver T, Nam Y, Gong TL, Lomax MI, Altschuler RA. 2001. Glial cell line-derived neurotrophic factor (GDNF) and its receptor complex are expressed in the auditory nerve of the mature rat cochlea. Hear Res 155:143-151.

Sutton D. 1983. Cochlear implant effects on the spiral ganglion. Ann Otol Rhinol Laryngol 92:316.

Suzuki M, Yagi M, Brown JN, Miller AL, Miller JM, Raphael Y. 2000 Effect of transgenic GDNF expression on gentamicin-induced cochlear and vestibular toxicity. Gene Ther 7:1046-1054.

Treanor JJ, Goodman L, de Sauvage F, Stone DM, Poulsen KT, Beck CD, Gray C, Armanini MP, Pollock RA, Hefti F, Phillips HS, Goddard A, Moore MW, Buj-Bello A, Davies AM, Asai N, Takahashi M, Vandlen R, Henderson CE, Rosenthal A. 1996. Characterization of a multicomponent receptor for GDNF. Nature 382:80-83.

Trupp M, Ryden M, Jornvall H, Funakoshi H, Timmusk T, Arenas E Ibanez CF. 1995. Peripheral expression and biological activities of GDNF, a new neurotrophic factor for avian and mammalian peripheral neurons. J Cell Biol 130:137-148.

Walsh ME, Webster DB. 1994. Exogenous GM1 ganglioside effects on conductive and sensorineural hearing losses. Hear Res 75:54-60.

Webster M, Webster DB. 1981. Spiral ganglion neuron loss following organ of Corti loss: a quantitative study. Brain Res 212:17-30.

West BA, Brummett RE, Himes DL. 1973. Interaction of kanamycin and ethacrynic acid. Severe cochlear damage in guinea pigs. Arch Otolaryngol 98:32-37.

Whitlon DS, Szakaly R, Greiner MA. 2001. Cryoembedding and sectioning of cochleas for immunocytochemistry and in situ hybridization. Brain Res Brain Res Prot 6:159-166.

Xing S, Furminger TL, Tong Q, Jhiang SM. 1998. Signal transduction pathways activated by RET oncoproteins in PC12 pheochromocytoma cells. J Biol Chem 273:4909-4914.

Yagi M, Magal E, Sheng Z, Ang KA, Raphael Y. 1999. Hair cell protection from aminoglycoside ototoxicity by adenovirus-mediated overexpression of glial cell line-derived neurotrophic factor. Hum Gene Ther 10:813-823.

Yagi M, Kanzaki S, Kawamoto K, Shin B, Shah P, Magal E, Sheng J, Raphael Y. 2001. Spiral ganglion neurons are protected from degeneration by GDNF gene therapy. JARO 4:315-325.

Ylikoski J, Pirvola U, Virkkala J, Suvanto P, Liang XQ, Magal E, Altschuler R, Miller JM, Saarma M. 1998. Guinea pig auditory neurons are protected by glial cell line-derived growth factor from degeneration after noise trauma. Hear Res 124:17-26.

Zha XM, Bishop JF, Hansen MR, Victoria L, Abbas PJ, Mouradian MM Green SH. 2001. BDNF synthesis in spiral ganglion neurons is constitutive and CREB-dependent. Hear Res 156:53-68. 